\title{
Corporal iluminação: simbolismo e textualização do vivido em A princesa e o pegureiro, de Abgar Renault
}

Solange Ribeiro de Oliveira Universidade Federal de Ouro Preto

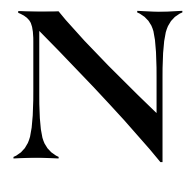

ove livros - coligidos em volume único, publicado pela Editora Record em 1990 - compõem Obra Poética, coletânea dos poemas selecionados por Abgar Renault para representar a produção poética de toda a sua vida: A Princesa e o Pegureiro, Sonetos Antigos, A Outra Face da Lua, A Lápide sob a Lua, Sofotulafai, Cristal Refratário, Íntimo Poço, Thanatos e O Rio Escuro. Nessa coletânea julgo possível, até certo ponto, ler a vida do autor: os poemas podem ser vistos como círculos concêntricos, ora mais próximos ora mais afastados de um eixo único, um auto-retrato, cujas feições emergem do tecido poético, linho de Verônica sulcado pelas feições de seu criador.

Evidentemente, não desconheço os riscos dessa afirmação. Consciente das problemáticas diferenças entre o discurso poético e o (auto)biográfico, e das complexas questões teóricas envolvidas, tenho sempre em vista o perigo de buscar correspondências diretas entre experiência vivida e prática escritural, as armadilhas da leitura unívoca, comprobatória e imediatamente referencial. Como não se cansam de repetir os estudiosos, o discurso literário, ficcional ou poético, caracteriza-se pela elaboração formal, pelos jogos (inter)textuais, constituindo antes uma transcriação que uma transcrição da experiência vivida. ${ }^{1}$ À semelhança de toda criação artística, deixa-se

${ }^{1}$ Refiro-me sobretudo aos trabalhos de LEJEUNE, 1973, p.137-162, 1983, p. 416-434, BARTHES, 1970, 1982, p. 13-21, BEAUJOUR, 1977, p. 442-458, BRUSS, 1977, 1974, p.14-26, DE MAN, 1985, EAKIN, 1985, FINKIELKRAUT, 1972, p. 155-169, FOUCAULT, 1982, p. 3-23, GUSDORF, 1991, LEJEUNE, 1973, p. 137162, 1983, p. 416-434, MIRANDA, 1992, STURROCK, 1993, ZAGURI, 1982. 
guiar por uma lógica sui generis, semelhante à dos processos oníricos, mais próximos do desejo que do registro factual.

Entretanto, não se pode negar que criação poética e vivência pessoal se interpenetram; um eu empírico, ainda que intermediado por múltiplas re-invenções, subjaz ao eu textual. A persona lírica, em algum momento, ajusta-se a um rosto, que, colando-se a sua máscara, também se reconstrói. Focalizando a intercessão de dados biográficos e criação literária, noto cautelosamente convergências e divergências. Sem esquecer a natureza ambígua, esquiva e "fingida" da relação entre arte e vida, julgo detectar na obra poética de Abgar Renault elementos para a elaboração de sua biografia literária, até agora escassamente tentada pela crítica.

$\mathrm{Na}$ leitura articulada de obra e vida, pretendo inicialmente focalizar o primeiro livro de Obra Poética, A Princesa e o Pegureiro, com uma breve referência à relação entre este e o livro seguinte, Sonetos Antigos. Além dos próprios poemas, e de comunicações orais de contemporâneos e familiares, recorro a dois grossos cadernos, perfazendo quase quatrocentas páginas, nos quais o poeta costumava colar recortes de textos, literários ou não, ligados a sua longa vida, incluindo a atuação como escritor, educador e homem público. ${ }^{2}$

Ao relacionar os dois livros iniciais de Obra Poética, tenho em mente que Sonetos Antigos, tal como A Princesa e o Pegureiro, pode ser lido sob uma perspectiva dupla: como textualização do vivido, e como testemunho da sucessão de estilos que, percorrendo momentos significativos da poesia brasileira, fazem da poesia de Abgar Renault um vasto painel pós-moderno. Os Sonetos, compostos entre 1921 e 1923, quando o poeta mal passava dos vinte anos, relacionam-se, por um lado, com uma experiência juvenil, um amor frustrado por uma jovem belohorizontina, cuja identidade deixo à curiosidade do leitor. Por outro lado, além de incorporar a idealização da amada, projetada como a dama inacessível do soneto petrarquiano, Sonetos Antigos constitui um exemplo de pastiche, pontilhado de tensões, oximoros e antíteses paralelas reminiscentes da escritura barroca e de alguns sonetos em que Camões antecipa o barroquismo. A Princesa e o Pegureiro mostra-se assim importante como realização poética: não apenas por seu inegável apuro

\footnotetext{
${ }^{2}$ Esse material inédito pertence ao arquivo do Prof. Affonso Henrique Tamm Renault, sobrinho de Abgar Renault.
} 
formal, mas, sobretudo, pela relevância do pastiche para a criação pósmoderna..$^{3}$

Sobre a paixão que inspirou os Sonetos, há, além, de relatos de contemporâneos e do próprio poeta a seus íntimos, uma referência jocosa, denominada "Indiscreções - Vultos da Faculdade Livre de Direito", assinada com o pseudônimo "Indiscreto" e inicialmente publicada na Revista Acadêmica da Faculdade. O texto explora comicamente uma crise amorosa vivenciada por Abgar, que, segundo "Indiscreto", poderia levar a uma tuberculose, a ser tratada nos hospitais de Barbacena, sua cidade natal:

Qual! Digam vocês o que quizerem, mas paixonite aguda é praga que, quando desembesta para cima de um christão, dá-lhe cabo do canastro! Bem andou a nomenclatura scientifica em chrismar com "ite" as peiores doenças deste mundo.

Há cousa de uns quatro annos conheci o Abgar, que era então a mais fagueira esperança do logar. Vibrante de espirito e de felicidade, era de vel-o na sua pose. Mas uma vez ( sempre o enfadonho mas ) a tal "tata juba" do amor deu-lhe uma arranhadela por deante, e o nosso heroe, de então por deante, entrou a decair até o ponto em que o vemos hoje - casulo murcho de onde desertou há muito a chrysallide da borboleta - illusão!

Excellente cidadão, embora não muito recommendavel pelo physico, exerce o nosso heroe, nas horas vagas, o officio de versejar - e verseja bem.

Sua mollestia... Homem, queira Deus que ella não o faça dar com os costados no "hotel" da linda terra em que nasceu!... ${ }^{4}$

As tinturas são cômicas, mas o quadro é real. Em 1921, Abgar está de fato apaixonado, e seus queixumes, disseminados em sua juvenilia inédita e prolongados em Sonetos Antigos, exprimem bem mais que uma postura literária convencional.

A exemplo do que ocorre em outras seqüências, a série de sonetos, simultaneamente exaltando e deplorando a virtude de uma dama recalcitrante, deixa vislumbrar uma história de amor, pontuada de súplicas,

\footnotetext{
3 Para o estudo de Obra Poética como texto pós-moderno, que remete a momentos significativos da poesia brasileira, cf. OLIVEIRA, 2001. p. 17-31.

${ }^{4}$ O texto, publicado na revista Footing em 12/06/1921, encontra-se à página 37 do primeiro caderno de recortes colecionados por Abgar Renault.
} 
recriminações, breves esperanças e céleres desenganos. A armadura formal, ilustrando a eleição do barroco como um modo de textualização da experiência, assenta como uma luva ao momento atravessado pelo jovem Abgar. Mal saído da adolescência, vivencia uma experiência amorosa que, somada a seu temperamento inquieto e conflituoso, encontra perfeita expressão no amálgama do barroco com a tradição petrarquiana.

Em seus contornos gerais, a narrativa implícita nos sonetos é verdadeira, como se afirma ter sido o amor de Camões por uma dama da corte: a moldura poética acomoda com elegância a paixão juvenil. As lágrimas celebradas nos Sonetos foram de fato derramadas mas não impediram o desfecho infeliz. Abgar amou verdadeiramente, com profundidade e desespero, renunciando, entretanto, a essa paixão, por se julgar mal correspondido. Assim, a caracterização convencional da dama esquiva e do frustrado amante convém à namorada indiferente e a seu cantor. A conclusão dos Sonetos em 1923 coincide aproximadamente com o fim da corte à jovem mineira. Convencido da inutilidade de suas demonstrações de afeto, e cansado de cultivar frustrações, o poeta finalmente renuncia ao amor que "em hum só curto momento/Anos me deu de fel à mocidade" (Soneto XVIII).

Abgar logo se interessa por outra jovem, iniciando a etapa decisiva de sua trajetória amorosa. Bonita e inteligente, com uma independência e clareza de propósitos rara entre suas contemporâneas, Ignez Brant, filha de Augusto Mário Caldeira Brant e Alice Dayrell Caldeira Brant (autora de Minha Vida de Menina com o pseudônimo de Helena Morley), inspira esse outro amor. Ignez ocupa logo um espaço privilegiado na vida de Abgar, tanto do ponto de vista afetivo quanto de sua vocação literária. É ela que inspira os poemas publicados quase setenta anos mais tarde com o título de A Princesa e o Pegureiro - texto em tudo contrastante com Sonetos Antigos. Ao novo amor, que é correspondido e conduzirá ao casamento, nem de longe assentaria o culto petrarquiano à dama desdenhosa. À persona poética já não convém a postura do apaixonado infeliz: prefere a máscara do pegureiro, o pastor romântico, humilde mas esperançoso diante de sua princesa. Em termos dos dons pessoais da jovem e de sua inexcedível importância na vida amorosa de Abgar, é compreensível que a persona poética a represente como princesa. Ao contrário da Ignez camoniana, Ignez Brant não precisou morrer para se tornar rainha: reinou por mais de sessenta anos no coração de seu pastor. Segundo depoimento do poeta, o amor por Ignez também explica seu desinteresse inicial pelo Modernismo - a experiência vivida dita a opção literária. 
Composto depois de Sonetos Antigos, que constitui o segundo livro, A Princesa e o Pegureiro aparece significativamente em primeiro lugar em Obra Poética. A inversão da seqüência cronológica remete á hierarquia amorosa. O amor por Ignez Brant sucede no tempo à celebração da namorada juvenil, a qual, entretanto, precede e supera em termos de sua múltipla influência sobre Abgar. Ao amor frustrado, tecido de adoração à distância, convinha a antiga fórmula, idealizada e abstrata, sem espaço para a expressão de percepções sensuais. O fato tem conseqüências importantes para a elaboração textual. Nos Sonetos a voz poética limitase a celebrar os olhos da amada, com vagas referências ao "lindo rosto manso". A dama permanece "aérea, intangível", "alada e immaterial". Em resumo, não tem corpo.

A Princesa e o Pegureiro, celebração de um amor correspondido, pinta um quadro radicalmente diverso. Sob o véu evanescente do Simbolismo, estilo dominante no livro, a persona poética rodeia o objeto cobiçado como algo tangível, quase ao alcance da mão. Um discreto erotismo, matizado pelos pudores da época, esgueira-se entre os versos, permitindo flagrar a lenta conquista de uma intimidade, até a "corporal iluminação" prefigurada no poema "Presente de Deus". A musa desce do pedestal, fazse mulher. Em poemas diferentes, suas feições, ao contrário da amada "aérea" e "imaterial" de Sonetos Antigos, vão sendo reveladas, até juntarse num corpo inteiro, de uma mulher real. Em "A Intangível Beleza", o pegureiro nota os "olhos de maio", "verdes, esveltos, evasivos", aprecia o sensual "esmorecer de suas pálpebras", mas não se detém no olhar, como nas composições adolescentes. Esgueirando-se entre os textos, rodeia "o alvo rosto do efêmero" ("Nas mãos de Deus/II"), "a alva luz da pele" ("Disfarce de Deus"), acaricia o "cabelo enastro" ("Alegoria"), confere as promessas eróticas dos lábios e da boca ("Soneto Romântico"), demora-se em suas curvas ("A Intangível Beleza"), buscando as mãos "ó carne! ó sonho! -" ("Aurora e Noite"). Não passa despercebida a promessa implícita nos "curvos braços feitos para se fecharem" ("A Intangível Beleza"), nem o contorno do corpo, que "embebeda de curvas e de azul todos os minutos de cada hora" ("Aurora e Noite"). Finalmente, o olhar amoroso desce ao detalhe de um "resto de unha" ("Sonho de Verão de uma Noite") ou dos " pés no chão" ("A Intangível Beleza"), detendo-se humildemente nos seus "sapatos velhos" ("Soneto Romântico").

Vislumbrado aos poucos, quase de esguelha, pela crescente ousadia da mirada lírica, o corpo, "alva composição de sonho e carne" ("Penúltima 
Tristeza"), mostra-se finalmente por completo, à espera da "mão de rei" que há de tocá-lo um dia:

Esquecer e Lembrar

Esqueço tudo que lembrar devia

porque te li e lembro esta leitura:

pés, braços, pernas (quase tu); o dia

nas mãos; a luz da vOz; a prematura

sombra no olhar imenso: a ausência fria

que não disfarça vida em sepultura;

a fronte grave; $\mathrm{o}$ andar que arrasta e guia

os homens; o verão sob a frescura

do corpo cheio de manhãs; os dentes

rindo branco na curva contagiosa:

o torso e o ventre sob a mesma lei.

do teu clima de mar; teus continentes;

o céu fechado e, nele, a lira e a rosa,

reino surdo, sem cetro e mão de rei.

A "corporal iluminação", que raia afinal para a persona poética, vai se revelando paralelamente com o desenrolar de uma história, que se inicia com a superação de antigas lembranças:

Desarrumei as cores já guardadas misturei o que foi e o que não é, lavro insônias, florestas e arquipélagos, e amo-te. ( "Eco")

O amor à primeira vista é anunciado em "Sub Specie Æternitatis ":

Vi-te, e sobre mim baixou, vinda do teu céu, uma fulguração de raio, que feriu de vertigem

o meu destino de distâncias e negações

e deixou meus olhos sem pálpebras

para outro sol que não seja o teu esplendor.

$\mathrm{Na}$ linguagem semi-cifrada, afim a um Simbolismo que só em parte embaça os contornos da realidade, não é difícil discernir os episódios, sempre iguais e sempre diferentes, da história amorosa, do primeiro encontro ao namoro e ao casamento: o silêncio inicial da jovem ("Alegoria"), as 
dúvidas de seu admirador ("Branca noite de luar"), a humilde espera ("Humildade") diante do corpo intocado ("Momento"), "verde fruto" ("Manhã"), que parece às vezes escapar ("Eco"). Seguem-se as angústias de ocasionais ausências ("Desespero", "Caos") ciúmes ("Caminhos do Esquecimento"), breves desentendimentos ("Desamparo") e reencontros tranquilizadores ("A Busca") .

O processo da conquista é, ao mesmo tempo, velado e intelegível. O erotismo contido vem à tona em poemas como "Se":

Se alguma coisa valesse

de certo valeria esse

urgente, doido esforço

por saber teu corpo moço,

por saber adivinhar,

com o pensamento e o olhar,

o corpo que a alma habita,

o corpo de alma finita.

A frustração do desejo transparece em "Entre o gesto e o búzio":

O teu gesto de chuva, de asa e lâmina

deserda o sonho entre meus braços nulos

(...)

e às aves da tristeza, que suplicam,

e aos enxames de abelhas, que carregam

desejo e mel, fechas os interstícios

de esquecimento e música infinita

que um minuto de ti pudera abrir

"Encantamento" também sugere a contenção, forçada pelos costumes da época, diante da "flor soterrada a sete chaves":

Tu és, às minhas mãos, fluida, fugace

como um sonho que nunca se sonhasse

ou como a sombra vã de outra sombra...

Insistente, a persona poética mantém-se atenta ao objeto do amor, quando balbucia: "Flores e ninhos buscam tua mão", em "Soneto do Equívoco", ou, com ousadia crescente, imagina a nudez subtraída à curiosidade amorosa: 
vestido cálido

que afagou as nebulosas,

o vinho, as ondas e as rosas

do teu subvertido corpo

("Em busca da estrela ")

A reticência desse lirismo não bloqueia imagens eróticas quase explícitas, como em "Flor":"Eu quero a espada de um minuto/ do teu espinho, ó flor aberta", ou em "Aî":

Refiz com meu degredo

teu vulto duvidoso

perdi-me em sua forma

de labirinto, flor

e casta nuvem pálida.

Entornei minha vida

- ah desolada tinta!

para afagar teus pés.

"Manhã" oscila entre a dúvida e a esperança da longa espera :

O desejoso chão de águas chorosas, este ar, a cor de dúvida das rosas

esperam com seu canto retardio

a chegada sem voz do teu minuto,

teu sorrir, tua luz, teu verde fruto

e o jamais do teu fúlgido navio.

"Corpo e Alma" recapitula o caminho percorrido até a consumação nupcial. Entretanto, o final feliz não encerra a luta, sempre renovada, por uma união que se quer ao mesmo tempo erótica e transcendental:

A junção das almas foi lenta, grave, mas, quando veio - criação diversa fechou-se numa chama casta, que ardia em pássaros e desconhecimentos.

A conjunção das almas foi penosa, porque o parto que buscavam cegas - e iria ser doeu na hora, antes de ser, e previu, no horizonte que baixava, a vermelha rosa. 


\begin{abstract}
A junção das almas foi no alto imenso.
Depois as almas descem aos seus corpos, veste cada qual a forma de sua carne arisca, e raízes entram, rasgam, doem silenciosamente.

O meu corpo é mais triste com a sua alma (serão todos os corpos mais tristes com suas almas?) por saber profundamente que todas as alturas e todos os mares da alegria podem habitar - e habitam intimamente - o teu corpo, esse infinito lugar.
\end{abstract}

Ao contrário do que geralmente sucede com celebrações poéticas, o canto nupcial não constitui o ponto final do livro. "Bodas de Diamante", último poema de A Princesa e o Pegureiro, só é escrito sessenta anos após o casamento:

Bodas de Diamante

Sessenta anos? Sessenta dias?

Duas vidas ou uma vida?

É uma só, e bem vivida.

Triste, sim, que o mundo é triste, mas, por igual, muita alegria que a alegria também existe, e a vida é múltipla mistura. A minha pálida fraqueza - confesso aqui com gratidão só encontrou um firme chão em tua excelsa natureza e em teu profundo coração e eu jamais quis outra ventura que me não desse a tua face ou o teu ser não retratasse.

O breve poema merece duplo destaque, tanto biográfico quanto literário. Resume a longa vida em comum, pontilhada de dores e alegrias, que incluem o nascimento de três filhos, a perda de um deles, os altos e baixos de uma carreira, as mudanças do casal de uma para outra capital brasileira, suas viagens pelo mundo e o apoio essencial da companheira, cujo caráter decidido equilibrou e complementou a sensibilidade do marido. Composto quando o poeta já roçava os noventa anos, "Bodas de Diamante", em contraste com os demais poemas do livro, testemunha, por outro lado, 
um extenso trajeto, da produção poética juvenil à da maturidade - ilustra, enfim, a versatilidade da obra. A beleza despojada do poema contrasta com a tonalidade estilística de A Princesa e o Pegureiro. No conjunto, apesar de já ter então eclodido o movimento modernista, o livro guarda o apuro formal e os contornos simbolistas ainda dominantes entre 1924 e 1926, quando foi composto.

Muitos anos depois, Abgar afirmará não se ter de pronto entusiasmado pelo Modernismo, que, no primeiro momento, associava à destruição formal e ao poema do tipo busca-pé. Atribui essa postura a sua formação parnasiana, fortalecida pelo contato com o poeta Vito Leão, hoje esquecido, que conheceu em Barbacena. Mas a causa principal do desinteresse é outra, que relembra o entrelaçamento entre história vivida e percurso literário. O próprio Abgar esclarece: "à época de A Revista eu namorava a moça com quem tive a ventura de casar-me e o que me interessava era escrever cousas que lhe agradassem e a comovessem... O mais nada importava para mim".

De fato A Princesa e o Pegureiro não deixa transparecer o advento do Modernismo, que só mais tarde iria refratar-se na obra do autor. Dando sua contribuição para o grande painel pós-moderno inaugurado com a publicação de Obra Poética em 1990, o texto de juventude permanece fiel à herança simbolista ainda presente na segunda década do século XX. No livro inspirado pela noiva predominam os sonetos, ao lado de canções, baladas e composições mais livres. Destacam-se as rimas ricas, as imagens refulgentes, a grandiloqüência, a adjetivação abundante, o vocabulário precioso Em contraste com a pretendida "objetividade" e precisão descritiva dos parnasianos, a sugestão e a evocação substituem a descrição e analogia explícitas. Valoriza-se a qualidade musical, "a hesitação prolongada entre o som e o sentido" pretendida por Valéry. O aspecto transcendental do Simbolismo manifesta-se no culto à Idéia essencial, incarnada na amada. Dessa perspectiva, a jovem cortejada em A Princesa e o Pegureiro aproxima-se às vezes da dama de Sonetos Antigos, como nos versos iniciais de "Sub Specie Æternitatis":

Vi-te e vi a expressão essencial da forma, da graça e da luz.

Vi-te e vi a trêmula fragilidade do efêmero vestida das roupagens do eterno.

${ }_{5}$ OLIVEIRA; RENAULT, 1996. p.44. 
Entretanto, aqui e ali, como testemunha "Bodas de Diamante", prenuncia-se a despojada beleza freqüente nos livros posteriores. Notase ainda, como uma constante em todos os livros de Obra Poética, algo que denomino "estética da negação ou do objeto sem função". Recorrente na obra de Abgar, essa estética individual pode ser ilustrada por expressões como "o sono sem sono" ("Desamparo") e em múltiplas imagens ligadas à idéia do oco, do vácuo, do vazio (típicas de poemas como "Caos", "Entre Mim e Mim" e "Sonho de Verão de uma Noite"). Ocasionalmente, nota-se ainda um jogo de antíteses, lembrando o barroquismo de Sonetos Antigos - outro traço que, como a estética da negação, sobrevive às múltiplas metamorfoses estilísticas. Estas, como a própria vida, continuam, compondo o grande mosaico pós-moderno que se desdobra em todos os livros de Obra Poética.

\section{Referências Bibliográficas}

BARTHES, Roland. Crítica e Verdade. Trad. Leyla Perrone-Moisés. São Paulo: Cultrix, 1970. . Le Discours de l'Histoire. Poétique, Paris: n. 49, p. 13-21, fev. 1982.

BARTHES, Roland et al. Literatura e Realidade. Trad. Tereza Coelho. Lisboa, Dom Quixote, 1984.

BEAUjOUR, Michel.Autobiographie et autoportrait. Poétique. Paris, n. 32, p. 442-458, nov. 1977.

BRUSS, Elizabeth.Autobiographical Acts: The Changing Situation of a Literary Genre. Baltimore: John Hopkins University Press, 1977.

. L'autobiographie considerée comme acte littéraire. Poétique. Paris: n. 17, p.14-26, 1974.

DE MAN, Paul. Autobiography as De-Facement. The Rhetoric of Romanticism. New York: Columbia University Press, 1985.

EAKIN, John. Fictions in autobiography. Studies in the art of self-invention. New Jersey: Princeton, 1985.

FINKIELKRAUT, Alain. L'autobiographie et ses jeux. Communications. Paris: n. 19, p. 155-169, 1972.

FOUCAULT, Michel. L'écriture de soi. Corps écrit. Paris: n. 5, p. 3-23, fév. 1982. 
GUSDORF, Georges. Auto-bio-graphy. Paris: Odile Jacob, 1991. . Les Écritures du Moi. Lignes de vie. Paris: Odile Jacob, 1991.

LEJEUNE, Fhilippe. Le pacte autobiographique.Poétique, Paris, n. 14, p. 137162, 1973.

. Le pacte autobiographique( bis ) Poétique, Paris 56, nov 1983, p. 416434.

MIRANDA, Wander Melo. Corpos Escritos. São Paulo/Edusp, Belo Horizonte, UFMG, 1992.

OLIVEIRA, Solange Ribeiro de e RENAULT, Affonso Henrique Tamm (Org.). Abgar Renault. Belo Horizonte: Centro de Estudos de Letras da UFMG, 1996.

OLIVEIRA, Solange Ribeiro de. Centenário de Abgar Renault, Poeta sem Rótulos. Revista da Academia Mineira de Letras. Belo Horizonte: Ano 79, volume XXII, set. 2001, p. 17-31.

STURROCK, John. The Language of Autobiography. Cambridge: at the University Press, 1993.

ZAGURI, Eliane. A Escrita do Eu. Rio de Janeiro: Civilização Brasileira, 1982.

\section{Resumo}

Centrando-se em A Princesa e o Pegureiro e Sonetos Antigos, os dois livros iniciais de Obra Poética de Abgar Renault, o texto explora a relação entre a experiência vivida e o discurso poético do autor, detendo-se particularmente nas variações estilísticas que, prosseguindo em sua prática escritural subsequente, contribuem para projetar o conjunto da obra como um vasto painel pós-moderno, representativo de toda a poesia brasileira no século XX.

\section{Abstract}

Focusing on A Princesa e o Pegureiro and Sonetos Antigos, the first two books of Abgar Renault's Obra Poética, the paper explores the relationship between poetic discourse and the author's lived experience, particularly stressing the stylistic variations which, underlying Renault's subsequent scriptural practice, contribute to project his work as a vast postmodern tableau, representative of the whole of twentieth-century Brazilian poetry. 